\title{
THE IMPACT OF DigITAL TRANSFORMATION Process OF THE RUSSIAN UNIVERSITY
}

\author{
Oleg Ipatov, Darina Barinova, Maria Odinokaya, \\ Anna Rubtsova \& Aleksey Pyatnitsky \\ Peter the Great St.Petersburg Polytechnic University
}
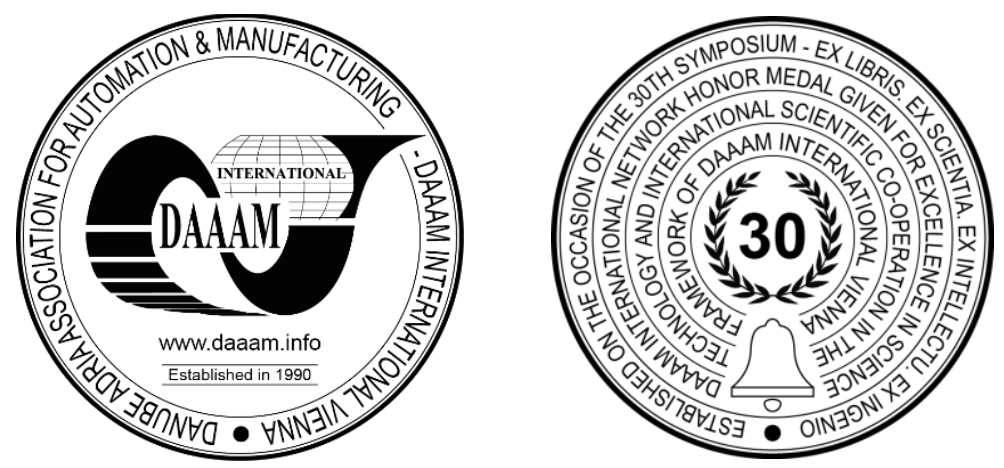

This Publication has to be referred as: Ipatov, O[leg]; Barinova, D[arina]; Odinokaya, M[aria]; Rubtsova, A[nna] \& Pyatnitsky, A[leksey] (2020). The Impact of Digital Transformation Process of the Russian University, Proceedings of the 31st DAAAM International Symposium, pp.0271-0275, B. Katalinic (Ed.), Published by DAAAM International, ISBN 978-3-902734-29-7, ISSN 1726-9679, Vienna, Austria

DOI: $10.2507 / 31$ st.daaam.proceedings.037

\begin{abstract}
The research topic of this paper is the impact of digital transformation process of the Russian university. The relevance of this study is determined by the role of education on the world stage during the period of a single cohesive large-scale digitalization, which is aimed at improving the quality of life and guaranteeing further prosperity, both for society and for each individual separately. A comprehensive coverage of issues related to digitalization in higher education is raised, including the disclosure of the essence of digitalization, consideration of the transformation that digitalization leads to, coverage of the features of the presentation of digitized information, challenges for Russian higher education. The paper examines learner's vision towards digital transformation in higher education. Identification of the key factors which have a major impact on the successful implementation of the transformation process in the education will be presented within the paper. The results of qualitative part of research indicate the influence of key factors on students and demonstrate their attitude to the digitalization process in the Peter the Great St.Petersburg Polytechnic University.
\end{abstract}

Keywords: Digital Transformation; Digital Knowledge; Digital Skills; Education; Russian university.

\section{Introduction}

The high rate of influx of a huge amount of data and the widespread global introduction of digital technologies are making rapid and significant transformations in all spheres of human life, including the education sector [1], [2]. In modern realities, the Internet is the basis of the global digitalization process. In our study, digitalization refers to the transformation (change) of an array of data into digital form so that they are more consistent with new tools and technologies of the digital economy and the subsequent exchange of this data through electronic communication channels. Digitalization is designed to perform routine tasks without the direct participation of the user, as well as for orientation in the modern world, since one of its characteristics is the systematization and ordering of data. 
In our study, we distinguish data and information. By information we mean that it contributes to the elimination of uncertainty. Information seems to be the main value. Data transfer to the Internet occurs through input devices, namely, gadgets. The digitization process makes information easy to understand, visual, personalized, increased availability in digital format [3]. Information is presented in digital form (digital twin). Digitized information is used to simplify specific operations. Digital transformation is about creating new applications that integrate all digitized data. There is a refusal from the participation of intermediaries, since tasks are transferred from a person to devices and into electronic systems for storage, processing, modelling and further transmission. Automation of processes in the educational sphere provides opportunities for both analytics and personalization of the educational process. Automation is understood as the transfer of processes existing in education in the form in which they exist at the moment to the base of computer calculations, electronic storage and exchange of data.

In connection with the comprehensive and all-encompassing process of informatization, some key questions are arised with the assessment of problem areas, the choice of specialized electronic platforms, the choice of software, the development of gadgets and the choice of digital methods of data processing, the issue of users' dependence on digital gadgets, the timely identification and elimination of technical illiteracy of users (readiness to master digital technologies, vulnerability to human negligence, loss of an array of data stored in electronic form due to technical failures of equipment, anticipation and avoidance of unplanned events). These problematic issues also affect educational institutions, especially higher education, as it plays one of the key roles in the digital transformation of society. The digital transformation of higher education is understood as the transformation (change) of its entire model, namely the strategy, processes, organizational structure for the most effective use of the possibilities of the digital economy.

The transition to digitalization in higher education must be carried out quite consciously and consistently. Therefore, in this paper we are going to focus on the key factors which have a major impact on the successful implementation of the transformation process in the education in the conditions of the digital transformation of society. By identifying the key factors for digital transformation affecting the educational system in Russia, the higher level of digital knowledge and skills development among the students will be analyzed and determined.

\section{Digitalization in education}

Currently, modern researchers are increasingly turning to the topic of digitalization in education. Issues related to the digitalization of education are considered by both Russian, in particular, Aladyshkin, Ipatov, Odinokaya, Krepkaia, Mitrofanova, Osipova, Tymoschuk and others, and foreign researchers, in particular, Khalin, Popescu, Castagna and others.

In connection with the emergence of the digital environment, profound systemic changes occur in society itself, the structure of institutions, the behaviour and interaction of objects of the social environment are changing. On the one hand, digital technologies as a tool of influence contribute to the creation of the reliability of educational results, ensure the accuracy of user identification. Parenting is also becoming digital, manifesting itself through the global Internet [4].

On the other hand, digitalization can have a number of disadvantages. "Technics are not neutral. Contemporary digital technologies claim to inform but more fundamentally they produce pulsions in a way that is destructive to psychic and collective individuation and leads to a generalized proletarianization, where the problem is not biopower or capitalism but lack of attention and desire" [5].

Some researchers point out that digital learning is designed to complement traditional learning and facilitate the acquisition of digital competencies necessary to thrive in the digital age [6]. The analysis of scientific research works made it possible to identify seven key factors which have a major impact on the successful implementation of the transformation process in the education:

- inviolability of personal space (a digital footprint remains in space), real threats of cyberattacks, cyberbullying [7];

- inhibition of some especially important psychophysiological functions and mental processes, such as motor skills, coordination, imagination, memory, speech, thinking [8]; the mentality and worldview of a person is changing, as well as the way of life [9];

- change in social behaviour; regulation of the relationship between people or a robot (social relations appear that did not exist before, for example, issues related to personal identification in the digital environment, the implementation of individual rights in the digital space) [10], [11], [12];

- risks of escape from reality;

- displacement of a person by a "smart" machine [13], [14];

- the aspect of adapting the educational process in the context of digitalization [15], [16];

- health risks [17], [18].

The following key factors are identified in Figure 1. 


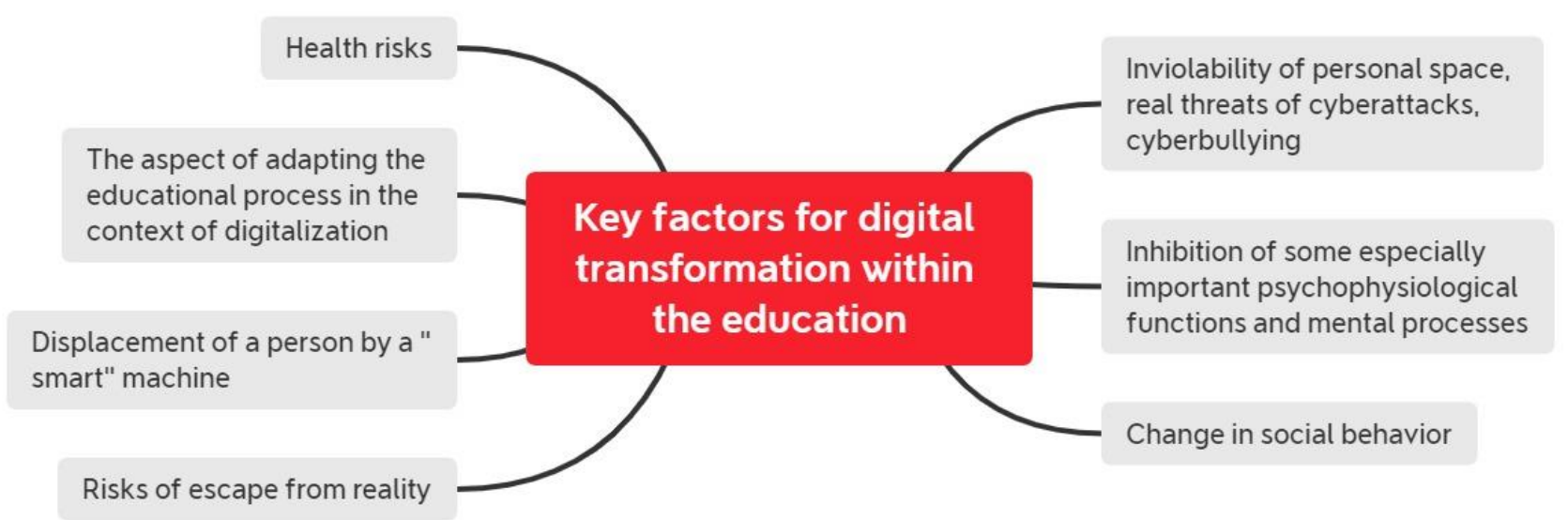

Fig. 1. A model of key factors for digital transformation within the education

To identify the factors that the introduction of digitalization brings to the educational process of higher education, we conducted a pilot survey of first and second year students. The study was conducted at the Peter the Great St.Petersburg Polytechnic University. Full-time polytechnic students were asked (27 people in each group) to answer a number of questions (Table 1).

\begin{tabular}{|l|}
\hline \multicolumn{1}{|c|}{ Questions } \\
\hline 1. What does the digitalization process itself bring to you personally in the aspect of education? \\
\hline 2. Do you feel in the process of studying that the process of digitalization is taking place? \\
\hline 3. In your opinion, will the digitalization process affect the social activity of students in the near future? \\
\hline $\begin{array}{l}\text { 4. How will the participants in the educational process, both teachers and students, have to adapt during the period of } \\
\text { digitalization? }\end{array}$ \\
\hline 5. In your opinion, how can digitalization affect the health of students and teachers? \\
\hline 6. Can the digitalization process affect the quality of the education process? \\
\hline 7. In your opinion, do you have the technical capabilities to study online? \\
\hline 8. In your opinion, does the culture of behaviour change with the advent of informatization in your country? \\
\hline
\end{tabular}

Table 1. Questions for the students

\section{Result and discussion}

Our research has revealed the following trends. Half of the respondents $(54 \%)$ noted positively regarding the introduction of digitalization into educational practice, the rest - negatively. Respondents noted that, in their opinion, traditional learning is much more effective than its digital counterpart. It is vitally important for students that the teacher is in the same space (classroom), that is, next to them. Also, the students noted that collective creativity is vital for them. The respondents also noted that they have more free time.

The overwhelming majority of respondents $(89 \%)$ said that the process was not so noticeable before the measures were taken against the coronavirus. The majority of respondents (65\%) said it was negative. We associate this with the fact that students are more and more in front of the monitors of computers and gadgets. We will have to introduce new courses for advanced training of teachers and open new educational educational programs within the university so that material can be taught, since the new environment requires new solutions. The respondents unanimously (100\%) stated that the introduction of digitalization could have a negative impact on health.

A quarter of respondents (37\%) believe that the quality of communication between participants in the educational process is improving. This is due to the fact that quality control is more stringent. There is a need to keep in touch between teachers and students. Only half of the respondents $(48 \%)$ noted that they have the necessary and necessary resources for online learning. All respondents $(100 \%)$ noted that the culture of communication behaviour with the advent of informatization in your country began to change.

Digitalization has several benefits. Thus, digitalization helps to resolve issues related to the accuracy of data provision. The information should be provided by the user from the original source. For example, a digitized document is available to both the teacher and the student. There is no need to repeat the same information many times, while there is a possibility of its distortion. 
Digitalization can have an impact on educational activities, both through complex technical knowledge, and through the possibly changing behaviour of learners. Already at the first stage of digitalization of the educational process, in many cases the need for physical presence for those users who have access to the Internet disappears. Digital accessibility bridges physical distance. The transition to digitalization in higher education must be carried out quite consciously and consistently, the introduction of strategic and tactical approaches is required [19], [20].

\section{Conclusion}

Based on the foregoing, we conclude that digitalization encourages humanity to work in a new format, manifested to a greater extent in management functions and settings in relation to performing actions directly. Digitalization has a multicontent nature, in particular, new relationships arise, their structure and connections are transformed. The introduction of digital achievements brings its own matrix of values, which is manifested in the availability of digital educational content, revision to the distribution of time and effort (comfortable conditions, optimal pace for the user), and the speed of information exchange. The process of rapid digitalization is alarming for many participants in the educational process. The trend of introducing digital achievements can be realized at the expense of scientific groundwork.

Although digital transformation is a very topical subject in the literature, knowledge about how to initiate digital transformation is still not profiled and there are not enough practical examples and experiences to help universities to take concrete steps. In order to the digital transformation process to be successful and lead to positive outcomes in higher education, six key factors have been identified which universities should acquire and develop when dealing with the transformation process. In this sense, the first research hypothesis is examined to determine whether the implementation of digital transformation is positive for students and what is their opinion.

The results of qualitative part of research indicate the influence of key factors on students and demonstrate their attitude to the digitalization process in the Peter the Great St.Petersburg Polytechnic University.With the provided insight into the current research effort in the field of digital transformation in the theoretical part, the main goal of the paper is to empirically investigate how digital knowledge and skills influences the digital transformation of universities in Russia. In order to the digital transformation process to be successful and lead to positive outcomes, seven key factors have been identified which universities should acquire and develop when dealing with the transformation process. In this sense, the first research hypothesis is examined to determine whether the implementation of digital transformation has positive outcomes among the students. With the provided insight into the current research effort in the field of digital transformation in the theoretical part, the main goal of the paper is to empirically investigate how digital knowledge and skills influences the educational system in the Russian university since the new environment requires new solutions.

The results showed that digital knowledge and skills, and abilities that the university is developing need to be improved. Acceptance of the hypothesis and conclusions of the theoretical part shows the relevance when using the concept of key factors which facilitate the process of digital transformation in the the educational system of Russia. The results of the qualitative research in this paper showed that students tend to be very concerned with the changes they face. It is required to strengthen the digital basis of the methodological support of Russian education, to develop competitive e-courses, to increase the competence of teachers in the new era.

\section{Recommendations and research limitations}

The conducted research has limitations which need to be taken into assessing the validity, reliability and generalization of results. There is a problem of bias, the respondent's subjective views and opinions. Another limitation is related to the analysed period of research which was determined by the coronavirus period when students were stressed and had to adopt to the new circumstances rather fast. The focus of this research is on the impact of the digital transformation on the educational system. The recommendation for future research is to include and analyse other universities in Russia, which would increase the research sample and will let us analyse the key factors and their impact for other universities in relation to the conducted research.

\section{References}

[1] Almazova, N.: Interactive Learning Technology for Overcoming Academic Adaptation Barriers. Proceedings of the Conference "Integrating Engineering Education and Humanities for Global Intercultural Perspectives". - Springer, Cham 786-794 (2020)

[2] Guerin C., Aitchison C., Carter S. Digital and distributed: learning and teaching doctoral writing through social media //Teaching in Higher Education. - 2020. - T. 25. - №. 2. - C. $238-254$. https://doi.org/10.1080/13562517.2018.1557138

[3] Gegenfurtner A., Schmidt-Hertha B., Lewis P. Digital technologies in training and adult education //International Journal of Training and Development. - 2020. - T. 24. - №. 1. - C. 1-4. doi: 10.1111/ijtd.12172

[4] Aladyshkin, I. V.: Development of Electronic Information and Educational Environment of the University 4.0 and Prospects of Integration of Engineering Education and Humanities. Proceedings of the Conference "Integrating Engineering Education and Humanities for Global Intercultural Perspectives” (Cham: Springer) 659-671 (2020) 
[5] Ipatov, O.: Pedagogical Assessment of General Professional Competencies of Technical Engineers Training. Proceedings of the 30th DAAAM International Symposium, B. Katalinic (Ed.) (Vienna: DAAAM International ) 0508-0512 (2020)

[6] Odinokaya, M.l: Self-Regulation as a Basic Element of the Professional Culture of Engineers. Education Sciences 9(3), 200 (2019) https://doi.org/10.3390/educsci9030200

[7] Krepkaia, T., Odinokaya, M., Sheredekina, O., Bernavskaya, M.: The culture of professional self-realization as a fundamental factor of student's internet communication in the modern educational environment of higher education. Education Sciences (Basel: MDPI) 9(3) 187 (2019) https://doi.org/10.3390/educsci9030187

[8] Mitrofanova E.A., Simonova M.V., Tarasenko V.V. (2020) Potential of the Education System in Russia in Training Staff for the Digital Economy. In: Ashmarina S., Mesquita A., Vochozka M. (eds) Digital Transformation of the Economy: Challenges, Trends and New Opportunities. Advances in Intelligent Systems and Computing, vol 908. Springer, Cham https://doi.org/10.1007/978-3-030-11367-4_46

[9] Tymoschuk N. A. Matrix Model of Cognitive Activity as One of the Meta Basis of Digital Education //Digital Transformation of the Economy: Challenges, Trends and New Opportunities. - Springer, Cham, 2020. - C. 481493. https://doi.org/10.1007/978-3-030-11367-4_48

[10] M Osipova and T A Naumova 2020 IOP Conf. Ser.: Earth Environ. Sci. 421032048

[11] Khalin V. G. et al. Digitalization and its impact on the Russian economy and society: advantages, challenges, threats and risks //Administrative Consulting. - 2018. https://doi.org/10.22394/1726-1139-2018-10-46-63

[12] Popescu, M.-F.; Chiripuci, B.-C.; Orîndaru, A.; Constantin, M.; Scrieciu, A. Fostering Sustainable Development through Shifting Toward Rural Areas and Digitalization-The Case of Romanian Universities. Sustainability 2020, 12, 4020. https://doi.org/10.3390/su12104020

[13] Lindberg S. Politics of digital learning - Thinking education with Bernard Stiegler, Educational Philosophy and Theory - 2020, 52:4, 384-396, DOI: 10.1080/00131857.2019.1586531

[14] Ferracane M.F. Redesigning Traditional Education. In: Feldner D. (eds) Redesigning Organizations. Springer, Cham-2020. https://doi.org/10.1007/978-3-030-27957-8_25

[15] Castagna, F.; Centobelli, P.; Cerchione, R.; Esposito, E.; Oropallo, E.; Passaro, R. Customer Knowledge Management in SMEs Facing Digital Transformation. Sustainability 2020, 12, 3899. https://doi.org/10.3390/su12093899

[16] Lee T., Kane Pham, Alexandra Crosby \& J. Fiona Peterson. Digital collaboration in design education: how online collaborative software changes the practices and places of learning, Pedagogy, Culture \& Society, 2020. DOI: $10.1080 / 14681366.2020 .1714700$

[17] Ashmarina S. I. Gaps in the system of higher education in Russia in terms of digitalization //Digital Transformation of the Economy: Challenges, Trends and New Opportunities. - Springer, Cham, 2020. - C. 437-443. https://doi.org/10.1007/978-3-030-11367-4_43

[18] Schmidt J.T., Tang M. Digitalization in Education: Challenges, Trends and Transformative Potential. In: Harwardt M., Niermann PJ., Schmutte A., Steuernagel A. (eds) Führen und Managen in der digitalen Transformation. Springer Gabler, Wiesbaden - 2020. https://doi.org/10.1007/978-3-658-28670-5_16

[19] Balogun N. A., Ahlan A. R., Awodele T. A. Digitalizing Bullying: Do Nigerian Students Get Cyberbullied? //2018 International Conference on Information and Communication Technology for the Muslim World (ICT4M). - IEEE, 2018. - C. 208-212. DOI: 10.1109/ICT4M.2018.00046

[20] Kazan H. Cyber Bullying and Violence Literacy in the Context of Digitalization //Handbook of Research on Multidisciplinary Approaches to Literacy in the Digital Age. - IGI Global, 2020. - C. 262-285. DOI: 10.4018/9781-7998-1534-1.ch013 